\section{THE EXTRACTION OF A BEAN FROM THE NOSTRIL.}

To the Editor of THE LANCET.

SIR,-While in medical charge of the Arrondissement of Studenitza by the Serbian Government, as Director of the Hospital at Raschka, surgery of a varied nature fell into my hands; and to me it is very questionable whether so-called minor surgery does not call for the exercise of one's wits quite as much as the more serious matter.

The staple article of diet of the country is the small bean, known as the French haricot; and in order to keep the children quiet they are given these beans with which to play, when the result is that they oft-times find their way into the nasal passages. On occasion the mother readily removes them, or ordinary forceps speedily settles the matter. In one case, however, a child 2 years of age was brought to me with a bean firmly wedged into the right nostril, so high up that the exercise of any force whatever bid fair, on account of the sensitiveness of the mucous membrane, to cause the onset of convulsions in the screaming child. One is told that soda-water wire makes an efficient instrument. But whence obtain it? And the bean may be pushed backwards into the gullet; in which case, however, one remembers the opening into the airpassages. I administered a whiff of chloroform; when, however, I came to use the forceps available they were ill adapted to seize the foreign body, and I was far removed from others of a finer nature. With an ordinary director, however, and making a fulcrum of the resilient mesial cartilage, the point of the instrument passing behind the bean, the latter, by gentle forward pressure, was readily brought to light.

I am, Sir, yours faithfully,

JoHN Furse McMrluaN, M.R.C.S.Eng., Late Royal Army Medical Corps.

Sandown, Isle of Wight., Nov. 5th, 1915.

\section{A "NEW SIGN" IN PULMONARY DIAGNOSIS.}

To the Editor of THE LANCET.

SIR,-My appreciation of the very valuable and enlightening attention which Dr. William Ewart has bestowed on the signs described by me, and of his very kind and flattering references to $\mathrm{my}$ humble thumpings is not the less real because this expression of it is somewhat belated. Dr. Ewart's two letters contain a mine of interesting information and speculation into which $I$ feel at the moment hardly qualified to probe, but what elicits my especial gratitude is the firm hold he has kept on the main facts, since these might so easily die of suffocation amid a crowd of theoretical considerations. "His transdorsal subresonance," he says, "and the scapular as well are undoubted realities"; and "the phenomenon itself matters much for us, much less its mechanism." This confirmation of the main facts and their significance, coming from so distinguished a source, seems to me most vital at this stage-at any rate it forms a most needful introduction to theoretical considerations as to their mechanism of production. With regard to this latter Dr. Ewart appears to favour thoracic muscle rather than lung as the explanation of the phenomenon, and $I$ am not in a position to refute his arguments. At the same time I do not feel convinced that the irfluence to which he alludes of "unfarourable" positions in nearly eliminating the bands of dullness may not be due to mere obscuration by muscular contraction of an underlying, but unaltered, lung change. In addition, I am still impressed with the absence of relationship of these bands of dullness, both upper and lower, with the distribution of the muscle layers of the back. As to the muscle groupings hinted at by Dr. Ewart in his letter of Sept. 18th as possibly responsible, or those suggested by Dr. Walter Verdon in THE LANCE'T of to-day (Oct. 30th), I should have considered that either could reasonably claim exoneration on grounds of "alibi." Dr. Ewart's discovery that the patient can himself appreciate the appearance and disappearance of the sign is a highly interesting point and might, as he suggests, facilitate its study.

Dr. Crawshaw Holt seems to me to have been mapping out the ground dullnesses of gross disease on to which the areas described by me are superimposed. Dr. C. Muthu's views of tuberculosis seem too revolutionary to invite discussion within the compass of a letter-so revolutionary, indeed, that I seem to see the word "pretuberculous" in his letter used with some justification for the first time; in the light of modern knowledge it is generally a misnomer, for which I am sometimes tempted to suggest the word "subtuberculous" as a substitute. His laudable caution against diagnosing pulmonary tuberculosis merely from impaired resonance certainly has my support, but tuberculosis can with advantage be suspected before it is diagnosed. Dr. Walter Verdon offers a myogenic explanation of the bands of impairment, as does Dr. Ewart. There are in his letter one or two phrases, possibly attributable to me, but for which I desire to disclaim responsibility. Thus he speaks of "the new signs pathognomonic of pulmonary tuberculosis described by Dr. Clive Riviere," but I do not hold them pathognomonic of tubercle, but rather common to all causes of irritation of the lung parenchyma. He remarks further that," the new sign is associated with shortening of the lungs" where I should have preferred to see "the new sign forms part of Abrams's reflex of contraction which is associated with shortening of the lungs," since the "shortening of the lungs" was not discovered by me. His separation, moreover, of the lower bands of dullness into inner, more constant, and outer less noticeable parts is, perhaps, a refinement from his own personal experience. I have no knowledge of this division.

At the conclusion I would like, if I may, again to lay stress on two points already touched on in $\mathrm{my}$ original communication.

Firstly, to those who find the bands of dullness and seek to utilise them in the diagnosis of disease I would urge that the sign be looked for before any, even the lightest, percussion of the chest wall be resorted to elsewhere, since otherwise, in some chests, the reflex may be unconsciously produced artificially.

Secondly, to those who experience difficulty in identifying the bands of dullness, I would recommend brisk friction of the back before an attempt is made to map them out. Such friction produces the "lung reflex of expansion" and heightens the contrast between the dull areas and the surrounding, now more resonant, lung (or must I say chest?). This manœuvre illustrates the highly curious fact about these two "reflexes of contraction and expansion" that they are by no means antagonistic and mutually exclusive since both can be, and often are, present at one and the same moment.

I am, Sir, yours faithfully,

Queen Anne-street, w., Oct. 30th, 1915. CLIVE RIVIERE. 